\title{
Utilising combined MPI and CACS results
}

We are thankful to Dr Sharma and colleagues, ${ }^{1}$ which clearly shows the benefit of combining myocardial perfusion imaging (MPI) and coronary artery calcium score (CACS) assessments. The two individual elements provide robust assessments of myocardial ischaemia. Combined, they juxtapose anatomical and functional perspectives. At our institution - and in many othersthe two investigations have to be done separately as the computed tomography (CT) component is not of sufficiently high resolution, being primarily intended for attenuation correction purposes only. ${ }^{2}$ Doing two separate scans is much less convenient for the patient.

With this combination, it was shown that patients with significant CACS findings during MPI had increased mortality and greater likelihood of poor LV function. This would no doubt translate to increased hospitalisations and hospitalisation costs. Hospitalisation costs are very high and the quest to reduce this mound is endless.

In Australia, the average cost per acute care admission was over $\$ 5000$. $^{3}$ We note that this figure encompasses a wide spectrum of medical conditions but chest pain was one of the three most common presentations. There is little doubt that being able to make use of the MPI/CACS combination would have significant medical, economic and psychosocial benefits (from people being out of hospital).
J Nucl Cardiol 2021;28:744.

$1071-3581 / \$ 34.00$

Copyright (c) 2021 American Society of Nuclear Cardiology.
So how can we make more effective use of MPI/ CACS data to reduce hospitalisations? We suggest utilising this information-taking patients with normal MPI but high CACS—and aggressively managing their cardiovascular risks. In this way, patients requiring more uncompromising risk factor management are more effectively selected. The question remaining in our minds is which risk factors should be prioritised given that the independent predictors of mortality (age, smoking, renal impairment, CACS) they have identified are not easily modifiable?

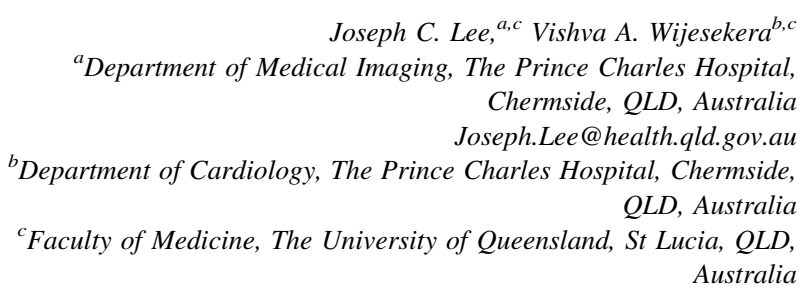

\section{References}

1. Sharma V, Mughal L, Dimitropoulos G, Sheikh A, Griffin M, Moss A, et al. The additive prognostic value of coronary calcium score (CCS) to single photon emission computed tomography myocardial perfusion imaging (SPECT-MPI)-real world data from a single center. J Nucl Cardiol. 2019. https://doi.org/10.1007/s12350-01901965-9.

2. Lee JC, West MJ, Khafagi FA. Myocardial perfusion scans. Aust Fam Physician. 2013;42:564-7.

3. National Hospital Costs Data Collection. What is the cost of Australia's admitted acute care patients? https://www.ihpa.gov.au/sites/default/files/ publications/national_hospital_cost_data_collection_australian_public_ hospitals_cost_report_round_21_2016-17_-_infographic_-_admitted_ acute_care.pdf. Accessed 26 January 2021

doi:10.1007/s12350-021-02564-3

Publisher's Note Springer Nature remains neutral with regard to jurisdictional claims in published maps and institutional affiliations. 